\title{
Educação Inclusiva:
}

Uma Contribuição da História da Psicologia

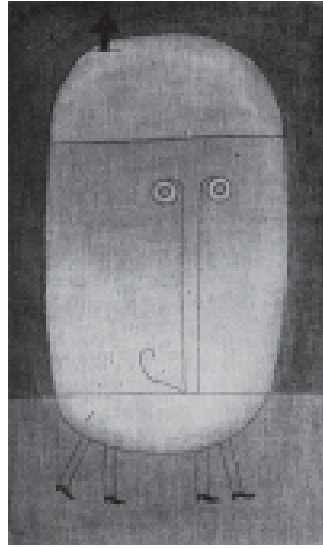

Érika Lourenço

Psicóloga, Formada pela Faculdade de Filosofia e Ciências Humanas da Universidade Federal de Minas Gerais (FAFICH-UFMG) em 1997.

Mestranda em Psicologia Social pela UFMG.

Ao longo da história da Psicologia a educação inclusiva vem se mostrando como um desafio. Este pode ser traduzido como uma mescla de novas perspectivas e métodos com as mais diversas críticas aos resultados obtidos. O trabalho da psicóloga e educadora Helena Antipoff com educação especial mostra como estas duas possibilidades podem estar presentes.

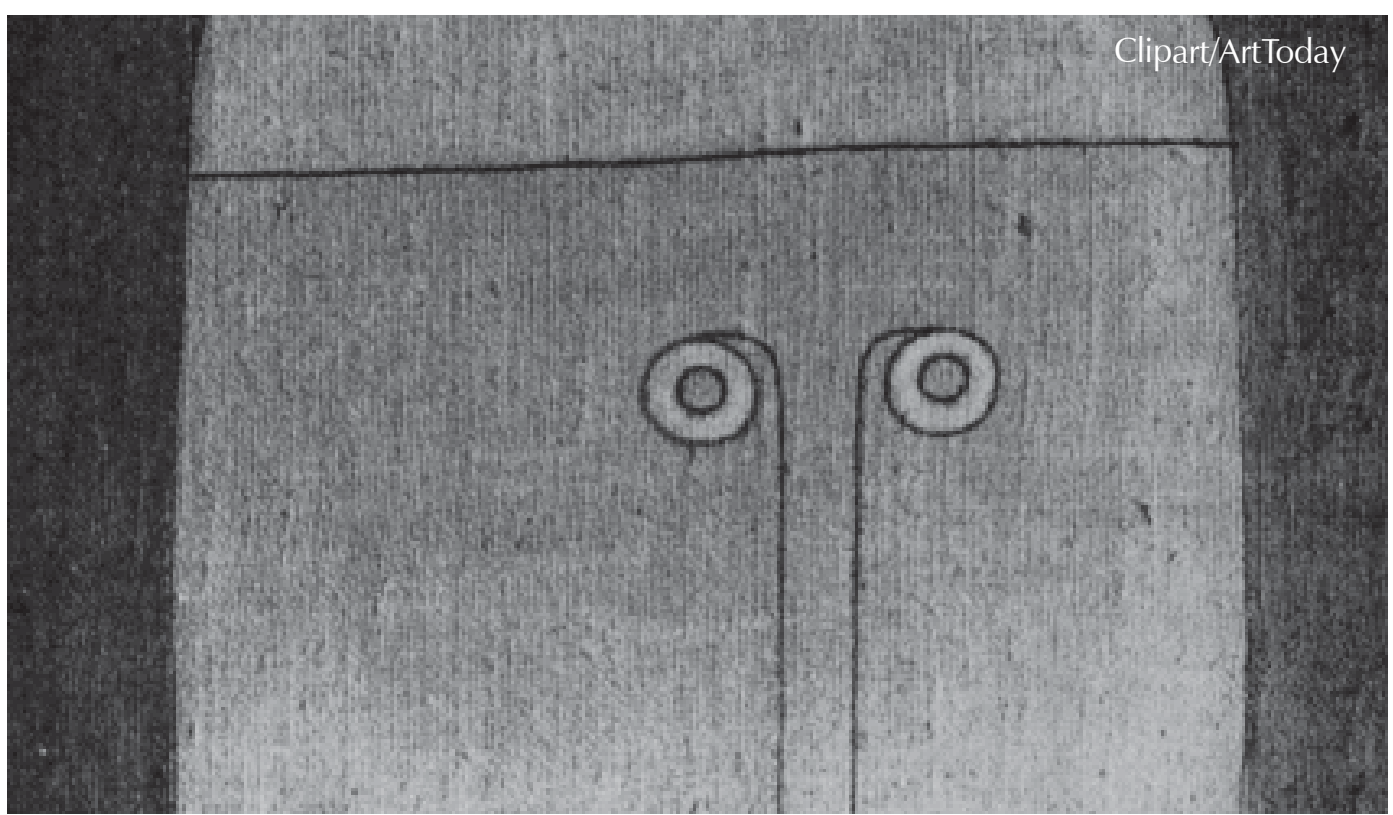

Refletir sobre a educação inclusiva implica pensar nas relações entre psicologia, práticas educacionais e educação especial, e, consequentemente, no papel social do psicólogo. Segundo Campos (1996), a história da ciência psicológica vem nos mostrando que a atuação do psicólogo, seja na educação, seja em outra área possível, jamais é neutra e responde a demandas que se inscrevem em um contexto político, econômico, social e cultural, estando sujeita a suas especificidades. Portanto, o resultado da intervenção do psicólogo pode ser bastante diverso das suas propostas iniciais, e, conforme denuncia Patto (1984), pode vir a legitimar práticas sociais que levam aos mais diversos tipos de discriminação.

Tal denúncia feita por Patto aponta para uma característica que, segundo Figueiredo (1995), marca a história da psicologia científica desde o seu surgimento no final do século XIX e que, conforme outros autores como Campos (1996), Bueno (1993) e Velho, este último citado por Wanderley (1999), vem se mantendo ao longo da história da disciplina, manifestando-se em muitas de suas diferentes propostas: a contradição entre o reconhecimento da subjetividade e das diferenças individuais, e, ao mesmo tempo, um movimento de controle destas diferenças através da construção de padrões de normalização. O resultado seria exatamente a geração de mecanismos de discriminação daqueles que não se enquadram nos padrões de normalidade.

Por estar relacionada exatamente com a diferença, podemos dizer que a atuação do psicólogo na área da educação do excepcional vem estando sujeita a tais contradições, e, conforme esperado, a muitas críticas. É a história, 
mais uma vez, que vem nos mostrar que o convívio com estas condições contraditórias constitui ora o grande desafio, ora a grande limitação do psicólogo que se dedica a esta área.

O caso da psicóloga e educadora Helena Antipoff, que empresta seu nome a este concurso monográfico, pode ser apresentado, ao mesmo tempo, como exemplo de como estas contradições surgem na relação entre psicologia e educação do excepcional e como dica dos caminhos a traçar no futuro.

Estudos referentes à relação entre psicologia e ideologia, como os de Patto (1984), e referentes à história da educação especial no Brasil, como os de Bueno (1993), tendem a considerar propostas como estas de Antipoff a partir de suas conseqüências práticas: a segregação e a exclusão das crianças excepcionais dos sistemas públicos de ensino.

Propomos aqui uma análise um pouco mais ampla das propostas de Antipoff - uma análise que aponte justamente as contradições que as permearam e que permita que se diferencie o contexto e os objetivos destas propostas de seu (inesperado) resultado segre-gacionista. Esta análise se fundamenta em uma leitura das Obras Completas de Helena Antipoff, publicadas pelo Centro de Documentação e Pesquisa Helena Antipoff em 1992. Estaremos assim, apresentando uma situação a que também hoje estão sujeitos os psicólogos que trabalham na educação do excepcional, seja na escola pública, seja em escolas especiais.

Helena Antipoff (1892-1974) nasceu na Rússia, mudando-se para a França em 1909. Fez sua formação superior na própria França, onde estagiou no Laboratório de Binet e Simon. Em seguida foi para a Suíça, estudando e trabalhando no Instituto Jean Jacques Rousseau, um dos principais centros propagadores das idéias da Escola Nova da Europa do início do século XX - o movimento das Escolas Novas constituiu-se a partir do final do século XIX e se caracterizou por novas propostas pedagógicas que enfatizavam a democracia nas relações escolares, uma educação que respeitasse as diferenças individuais, as aptidões e os interesses das crianças. Antipoff especializou-se, portanto, em Psicologia da
Educação. Por ocasião da Primeira Guerra Mundial, voltou à Rússia, onde viu eclodir a Revolução de 1917. Neste país permaneceu até o ano de 1924, engajando-se num trabaIho de triagem e reeducação das crianças órfãs e abandonadas em decorrência dos conflitos militares. De volta a Genebra, voltou a se integrar à equipe do Instituto Jean Jacques Rousseau (Antipoff, 1975).

Antipoff permaneceu em Genebra até 1929, quando veio ao Brasil a convite do governo de Minas Gerais para trabalhar na reforma do ensino do estado. Dentre as múltiplas propostas vinculadas a esta reforma, estava a formação das professoras das escolas públicas em psicologia da criança e nos novos métodos divulgados pelo movimento das Escolas Novas que estavam em voga na Europa e nos Estados Unidos. Para este fim, algumas professoras foram enviadas para fazer cursos nos Estados Unidos, enquanto professores estrangeiros foram convidados para ministrar cursos para as professoras que aqui permaneceram. Foi criada em Belo Horizonte a Escola de Aperfeiçoamento de Professoras e Antipoff foi convidada para aí dar aulas de psicologia da infância e ajudar na implantação da reforma nas escolas públicas mineiras.

Uma das primeiras atividades na qual Antipoff se envolveu em Minas Gerais foi a homogeneização das classes das escolas públicas. Esta proposta deve ser considerada no contexto em que surgiu: o ideário escolanovista separadas em classes homogêneas, as crianças receberiam uma educação orientada por seus interesses individuais e sob medida para o melhor desenvolvimento de suas capacidades. Foi em meio a esta atividade de separar as crianças segundo seus interesses e aptidões individuais que Antipoff se deparou pela primeira vez no Brasil com a causa das crianças excepcionais, causa esta que abraçaria pelo resto da vida e que traria a marca da contradição que anteriormente mencionamos.

A partir deste momento inicial de descoberta de um grande número de crianças que acabavam por ficar excluídas do sistema público de ensino, suas propostas em educação especial podem ser divididas em dois momentos bastante específicos: a atuação em prol das classes especiais nas escolas públicas de Minas 
Gerais e, depois, sua atuação na educação dos excepcionais na Fazenda do Rosário.

Aqui é importante ressaltar que apesar das diferenças e contradições que marcaram estes dois momentos de sua obra e dos resultados de suas intervenções, em ambos os momentos, Antipoff pensava na inclusão dos excepcionais, seja em um sistema público de ensino, seja na sociedade.

Antipoff no processo de homogeneização das classes das escolas públicas percebeu que havia um grande contingente de crianças portadoras dos mais diversos graus e tipos de necessidades especiais colocadas em classes comuns. Os professores, segundo sua observação, não possuíam qualquer preparação ou mesmo interesse para promover meios para a educação destas crianças. Assim, deixadas à parte do andamento da turma como um todo, seu destino era a múltipla repetição de ano, até a desistência dos estudos.

Estando previsto nas leis do ensino a existência das classes especiais nas escolas públicas, Antipoff, atuando junto às professoras alunas da Escola de Aperfeiçoamento, tentou fazer com que funcionassem. Programou a seleção e distribuição dos alunos de acordo com suas necessidades e com seu grau de desenvolvimento físico e mental. Enfatizou a necessidade de turmas pequenas, de um ensino individualizado, de um ambiente adequado, com material didático disponível e professoras bem preparadas.

Considerava-se preciso dar a cada um uma educação que permitisse seu máximo desenvolvimento. A regra era válida também para os portadores de necessidades especiais. Esta era não só a proposta da Escola Nova, mas também da Declaração de Genebra, uma declaração dos direitos das crianças que foi promulgada após o término da Primeira Guerra Mundial e que Antipoff, em sua experiência no Instituo Jean Jacques Rousseau aprendeu a tomar como fundamento de sua prática (Lourenço, 1998).

Por outro lado, estava embutida nestas mesmas propostas uma visão organicista da excepcionalidade. Havia a crença em que, através da educação, dos exercícios de “orto- pedia mental" incluídos nas atividades escolares - exercícios lúdicos para o treino e a melhoria das capacidades mentais como atenção, memória etc. - estas crianças poderiam ser curadas de seus desvios. A educação era então vista como um meio de evitar que a anormalidade trouxesse influências nocivas para a sociedade, conforme observa Aun (1994).

Aí podemos apontar uma contradição - uma idéia democrática, de uma escola pública para todas as crianças, atendendo às suas necessidades e visando seu máximo desenvolvimento em contraposição à idéia de excepcionalidade como um problema a ser sanado, uma doença a ser curada.

Ainda segundo Aun (1994), o resultado destas propostas não foi outro senão a segregação das crianças excepcionais, o que se deu em vários níveis. Não só na separação das crianças em classes diferentes, mas no pouco interesse que estas classes despertaram nas professoras, o que implicou no não atendimento das propostas de uma educação especial - exatamente o oposto do esperado.

A própria Antipoff percebeu que a escola pública e a Escola de Aperfeiçoamento pouco vinham conseguindo fazer pela infância excepcional e em 1932 criou a Sociedade Pestalozzi de Belo Horizonte. Esta foi uma alternativa para angariar a assistência necessária à complementação do treinamento das professoras no ensino do excepcional, do diagnóstico psicológico e do atendimento clínico oferecidos no Laboratório de Psicologia da Escola de Aperfeiçoamento Pedagógico.

Com o crescimento do número de associados e da atuação da Sociedade Pestalozzi ao longo das décadas de 30 e 40, foram aumentando os serviços prestados às crianças das classes especiais visando o diagnóstico psicológico e físico, novas propostas educacionais, tratamento médico e pesquisas para a compreensão científica da excepcionalidade.

Aos poucos, à medida que aumentava seu contato com as crianças excepcionais, a concepção organicista da excepcionalidade que Antipoff adotava foi sendo transformada em uma visão mais abrangente. Segundo Aun 
(1994), deixando de enfatizar a necessidade de cura de uma deficiência ou de prevenção de suas influências negativas para o futuro desenvolvimento da sociedade, o cerne das suas intervenções passou a ser o meio físico e social no qual a criança estava inserida. $\mathrm{Na}$ prática, esta proposta tão diversa da anterior atingiu o auge na Fazenda do Rosário, marcando o que podemos considerar um segundo momento da atuação de Antipoff em educação especial.

Enfatizando o papel do meio ambiente na produção da excepcionalidade e na forma de com ela lidar, de acordo com Antipoff (1992), a cidade não seria o local mais indicado para a educação das crianças excepcionais. Em suas palavras:

"Escolas para excepcionais devem ser localizadas fora das cidades. O local natural é o campo. Espaços mais largos permitem movimentos mais amplos. Os ritmos da vida são ali mais regulares: o sol, melhor que o relógio, e os sinos marcam as horas, convidando ao trabalho e ao sono.(...) A estética do ambiente é o fundo no qual se perfilarão as ações dos adolescentes. Esses, rapidamente, eles mesmos, ou com o auxílio dos educadores, procurarão a harmonia, fugindo do chocante visível e da cacofonia das discordâncias. E, assim, paulatinamente, se aproximam das regras da vida social e moral." (p.149-150).

Em 1940 parte da Sociedade Pestalozzi foi transferida para o município de Ibirité, localizado a pouco mais de $20 \mathrm{~km}$ de Belo Horizonte - aí fora comprada, com a verba angariada pela própria Sociedade Pestalozzi, a Fazenda do Rosário. Foi aberta na Fazenda do Rosário uma escola, com vagas para crianças e adolescentes excepcionais que não conseguiam se adaptar às escolas públicas ou por elas ser aceitos.

O conceito de excepcionalidade adotado por Antipoff (1962) foi ampliado. A educação especial passou a ser endereçada a "crianças e adolescentes que se desviam acentuadamente para cima ou para baixo da norma de seu grupo em relação a uma ou a várias características mentais, físicas ou sociais, ou qualquer destas de forma a criar um problema essencial com referência à sua educação, desenvolvimento e ajustamento ao meio social."(p.10).
Funcionando no modelo construtivista, a escola oferecia diversas atividades, onde a criança podia, no contato com a natureza e com o instrumental disponível, sob a orientação de professoras devidamente treinadas, exercitar e desenvolver, de forma lúdica, suas habilidades e funções mentais.

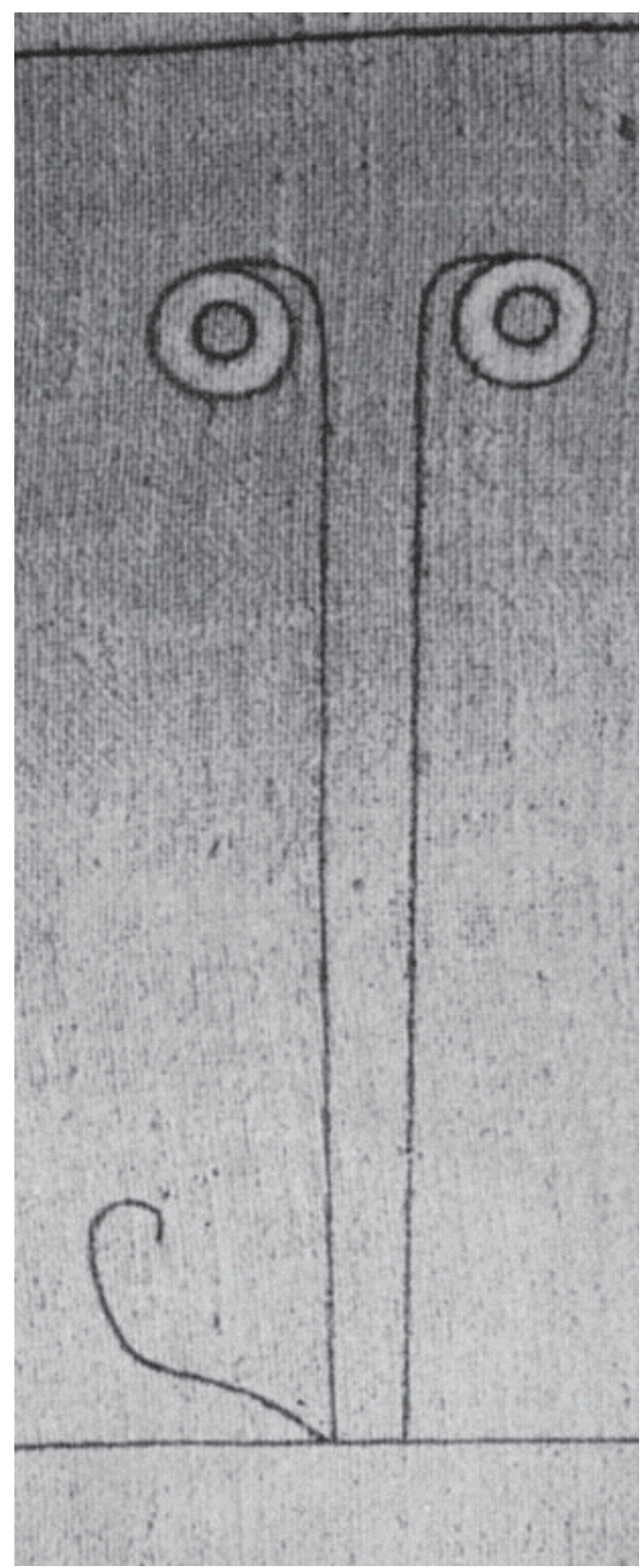

Paralelamente às aulas, eram oferecidos serviços e assistência médica, odontológica, psicológica, cursos para preparação de professores, palestras para orientação de familiares e voluntários que cuidavam de excepcionais. 
Além disso, havia o acompanhamento sistemático do desenvolvimento de cada aluno nos níveis somático e psicológico, visando a avaliação do trabalho realizado e o melhor conhecimento científico das diversas disfunções apresentadas pelas crianças e adolescentes.

Outro aspecto ao qual se dava atenção era a preparação para a inclusão da criança na vida social fora da Sociedade Pestalozzi. Diversas das atividades oferecidas visavam não só o desenvolvimento das funções mentais, mas também o desenvolvimento moral e a socialização da criança. Nas diversas oficinas a que tinham acesso, os alunos aprendiam um ofício que seria útil como meio de ganhar a vida fora da Fazenda do Rosário. Também esta saída dos alunos era acompanhada, de forma a permitir a adaptação gradual do aluno a um novo ambiente.

Consciente de que tinha um papel social a cumprir, de que não podia se omitir frente a um problema identificado a partir de sua atuação em psicologia da criança, Antipoff, em seu tempo, foi incansável na elaboração e avaliação de propostas para uma educação especial. Na Fazenda do Rosário a proposta educacional da Escola Nova foi eficazmente aplicada à educação especial. Aí as propostas

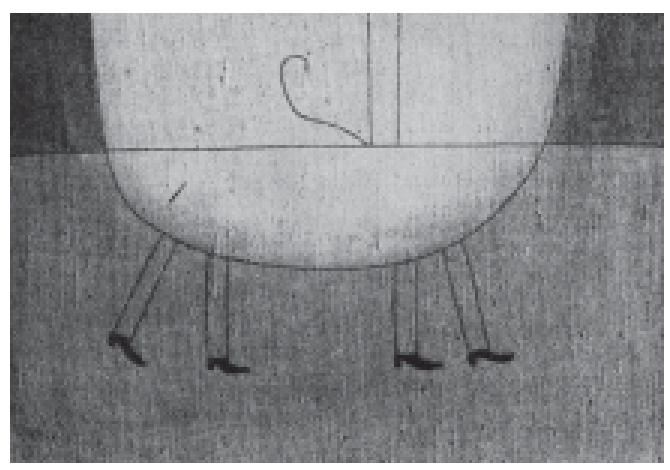

da Escola Nova assumiram o caráter democrático desejado por Antipoff, sendo usado para a melhoria das condições de educação não só das crianças que se enquadravam nos padrões de normalidade, mas também daquelas que, por algum motivo se desviavam deste padrão - e que, nas escolas públicas acabavam por ser excluídas do sistema educacional.

Com uma nova concepção acerca do caráter da excepcionalidade, parte da contradição que marcara as intervenções anteriores desapareceu. Era ampla a preocupação com o desenvolvimento físico, psicológico, moral e social das crianças. Também sua reinserção na sociedade era alvo de intervenção, enfatizandose a necessidade de um acompanhamento dos adolescentes nesse processo que deveria ser gradual.

Entretanto esta proposta surgiu em um determinado cenário social, não deixando de se sujeitar às suas condições. Mesmo que no interior da Fazenda do Rosário o pensamento de Antipoff se concretizasse em um modelo de educação democrática, o fato de seu funcionamento ocorrer no campo, afastado da vida social comum, gerou novas contradições. Desta vez, relacionadas à reinserção dos adolescentes à sociedade. Apesar de diversos dos ex-alunos haverem conseguido de forma satisfatória esta reinserção, permaneceu a crítica à localização da escola no meio rural e às dificuldades deste processo de reinserção. Hoje, é a pesquisa histórica que vem resgatando o pensamento que estava por trás dos resultados alcançados e as contradições que ele manifesta: desejo de inclusão e justificativa da segregação.

Com este relato o que pretendemos apresentar não foi um modelo de atuação. Quisemos, ao contrário, mostrar que a prática psicológica na educação das crianças excepcionais está sujeita às influências do pensamento de seu tempo e, por isto, sujeita também a resultados que podem se mostrar ou ser interpretados de maneira bastante diversa da que se propunha.

Atualmente, as questões que são pertinentes quando consideramos a prática da psicologia na educação do excepcional não são muito diferentes daquelas que inspiraram as propostas de Antipoff. Entretanto o referencial teórico-prático que temos disponível é outro. Está na pauta dos debates a proposta de educação inclusiva, já que a LDB propõe que as crianças excepcionais sejam aceitas nas classes comuns das escolas públicas e que as escolas especiais sejam coadjuvantes no processo educacional destas crianças. De acordo com Lüscher (1999) discute-se a forma pela qual se dará este processo, a necessidade de preparação das professoras e das outras crianças 
visando evitar a discriminação. Já estão também sendo apontadas algumas dificuldades para o processo, como o caso de escolas que se recusam a aceitar a matrícula das crianças excepcionais.

Em síntese, hoje, diversas são as propostas, os eixos de discussão e os problemas que aparecem em torno da educação inclusiva - e, vale ressaltar, todos sujeitos às contradições apontadas, pois, de acordo com o discurso vigente, ao mesmo tempo em que se propõe a inclusão, teme-se que esta gere a segregação. Entretanto, tais sujeições, tais temores, tais possibilidades não devem levar à paralisação e nem devem ser tomadas como limites intransponíveis, mas como desafios para as novas propostas. Que estas sejam planejadas e implantadas com um cuidado, preparação de pessoal e avaliação tais que no futuro se possa perceber que houve realmente a inclusão, pois, sabendo das contradições possíveis de aparecer na mais inocente e bem intencionada idéia, sabemos o bastante para não mais esperar que só o futuro avalie os resultados das nossas intervenções.

Faz-se por isso necessário que nós psicólogos tenhamos sempre em mente que nossas propostas e intervenções têm efeitos sociais que não podem ser desprezados. Assim, poderemos pretender atuar de forma a fazer com que os ideais de uma educação democrática (leia-se aí inclusiva) de hoje não se tornem futuros instrumentos de segregação.
Antipoff, D. (1975). Helena Antipoff, sua Vida, sua Obra. Rio de Janeiro: José Olympio.

Antipoff, H. (1992). Educação dos Excepcionais. Em COLETÂNEA de Obras Escritas de Helena Antipoff - Educação do Excepcional (pp.149150). Belo Horizonte: Centro de Documentação e Pesquisa Helena Antipoff.

Antipoff, H. (1962). Sociedade Pestalozzi de Minas Gerais. Infância Excepcional. Belo Horizonte: Sociedade Pestalozzi.

Aun, J. G. (1994). Transformações no Conceito de Excepcionalidade em Instituições Organizadas Sob a Influência de Helena Antipoff. Em Boletim do Centro de Documentação e Pesquisa Helena Antipoff. Belo Horizonte: Centro de Documentação e Pesquisa Helena Antipoff, 14, n.12, 8-26.

Bueno, J. G. S. (1993). Educação Especial Brasileira: integração/segregação do aluno diferente. São Paulo: EDUC.

Campos, R. H.de F. (1996). Em Busca de um Modelo Teórico para o Estudo da História da Psicologia no Contexto Sociocultural. Coletâneas da ANPEPP. São Paulo: EDUC, 1, n.15.

Centro de Documentação e Pesquisa Helena Antipoff (1992). COLETÂNEA de Obras Escritas de Helena Antipoff - Educação do Excepcional. Belo Horizonte, v. 3 .
Centro de Documentação e Pesquisa Helena Antipoff (1992). COLETÂNEA de Obras Escritas de Helena Antipoff - Educação Rural. Belo Horizonte, v. 4

Centro de Documentação e Pesquisa Helena Antipoff (1992). COLETÂNEA de Obras Escritas de Helena Antipoff - Fundamentos da Educação. Belo Horizonte, v.2.

Centro de Documentação e Pesquisa Helena Antipoff (1992). COLETÂNEA de Obras Escritas de Helena Antipoff - Psicologia Experimental. Belo Horizonte, v.1.

Figueiredo, L.C. (1995). Psicologia - uma introdução. São Paulo: Educ.

Lourenço, É. (1998). Educação Especial no Pensamento de Helena Antipoff (1912-1974). Anais da V Semana de Pesquisa da FAE (pp. 167-179). Belo Horizonte: FAE/UFMC.

Lüscher, A. Z. de C.(1999). Educação Especial: inclusão e exclusão. Em Presença Pedagógica, 5, n.28, 81-84.

Patto, M. H. S. (1984). Psicologia e Ideologia. São Paulo: T.A. Queiroz.

Wanderley, F. (1999). Normalidade e Patologia em Educação Especial. Em Psicologia: Ciência e Profissão, 19, n.2, 2-9.
Referências bibliográficas 